\title{
Morfologia de frutos, sementes e plântulas de Canavalia dictyota Piper (Leguminosae, Papilionoideae)
}

\author{
Edmar da Silva Prado $^{1} \&$ Rodrigo Schütz Rodrigues ${ }^{1}$
}

\author{
${ }^{1}$ Universidade Federal de Roraima, Centro de Estudos da Biodiversidade, Campus do Paricarana, Av. Ene Garcez \\ 2413, CEP 69304-000, Boa Vista, RR, Brasil. E-mails: edhurameshi@hotmail.com; rodschutz@gmail.com
}

Recebido em : 17/01/2013. Aceito em: 21/02/2013.

\section{RESUMO}

Canavalia DC. é um gênero pantropical de Leguminosae-Papilionoideae, com cerca de 60 espécies. Este trabalho tem como objetivo descrever e ilustrar a morfologia de frutos, sementes e plântulas de Canavalia dictyota Piper. Frutos maduros de $C$. dictyota foram coletados em Boa Vista, Roraima, Brasil. A espécie apresentou fruto do tipo legume, reto, simples e unisseriado, com 4-7 sementes por fruto. As sementes são exalbuminosas e apresentaram hilo linear. As plântulas são fanero-epígeasarmazenadoras, com eofilos do primeiro nó 1-foliolados, opostos e com estípulas inteiras ou bilobadas. Por fim, o trabalho apresenta uma breve revisão sobre plântulas de Canavalia e discute a variação morfológica encontrada no gênero.

PALAVRAS-CHAVE: Fabaceae, legume, Phaseoleae, desenvolvimento pós-seminal

\section{ABSTRACT}

Canavalia DC. is a pantropical genus of Leguminosae-Papilionoideae, with about 60 species. This work aims to describe and illustrate the morphology of fruits, seeds, and seedlings of Canavalia dictyota Piper. Mature fruits of $C$. dictyota were collected from wild populations in Boa Vista, Roraima State, Brazil. The species has a straight, simple, uniseriate legume, which has 4-7 seeds per fruit. The seeds are exalbuminous, and have a linear hilum. Canavalia dictyota possesses phanerocotylar seedlings with storage (reserve) cotyledons, eophylls at the first node that are 1-foliolate and opposite, and entire or bilobate stipules. This work also presents a brief revision on seedlings of Canavalia, and discusses the morphological variation found in the genus.

KEY WORDS: Fabaceae, legume, Phaseoleae, post-seminal development

\section{INTRODUÇÃO}

Estudos morfológicos de frutos, sementes e plântulas são importantes para a obtenção de caracteres taxonômicos, contribuem na interpretação da fisiologia do armazenamento e germinação de sementes, sucessão ecológica, dispersão e de interações com a fauna (Garwood 1995).

Em Leguminosae, família com destacada importância ecológica e econômica (Lewis et al. 2005), estudos de Gunn (1981; 1984) e Kirkbride et al (2003) são os trabalhos de referência para a caracterização morfológica de frutos e sementes. Por sua vez, informações sobre a morfologia de plântulas de leguminosas foram compiladas por Duke \& Polhill (1981) e recentemente por Gurgel et al. (2012). Contudo, para o Brasil, os estudos marcadamente se concentram em táxons arbóreos (e.g. Lima 1990; Oliveira 1999; Rodrigues \& Tozzi 2008), sendo pouco enfatizados grupos herbáceos (Gonçalves et al. 2008; Rodrigues et al. 2012).
Canavalia DC., pertencente à subfamília Papilionoideae, tribo Phaseoleae, apresenta espécies herbáceas (reptantes ou trepadeiras) ou lianas, e geralmente possui flores vistosas e frutos do tipo legume (Sauer 1964; Schrire 2005). Canavalia apresenta distribuição pantropical com cerca 60 espécies, das quais 33 ocorrem no Novo Mundo e 17 no Brasil (Schrire 2005; Queiroz 2012). Algumas espécies de Canavalia são amplamente utilizadas na agricultura como forragem, plantas de cobertura e adubo verde, sendo também utilizadas para alimentação animal pela alta concentração de proteínas assimiláveis (27\%$29 \%$ ) que possuem especialmente as suas sementes (Beyra et al. 2004; Sauer 1964).

Para Phaseoleae, Baudet (1974) apresentou uma revisão da morfologia de plântulas envolvendo 109 espécies de 25 gêneros da tribo, incluindo Canavalia. Dados sobre plântulas ainda são escassos para espécies de Canavalia (Compton 1912; Baudet 1974; Sastraprajda et al. (1976); Sanches \& Válio 
2002; Gonçalves et al. 2008). Para espécies neotropicais, existem descrições e ilustrações somente para C. Canavalia ensiformis (L.) DC. e C. rosea (Sw.) DC. (Baudet 1974; Gonçalves et al. 2008).

Espécies de Canavalia ocorrentes na Amazônia ainda não foram estudadas quanto à morfologia de frutos, sementes e plântulas. Uma das espécies amazônicas é Canavalia dictyota Piper, que ocorre nos trópicos da América do Sul, com extensão ao Caribe e América Central (Sauer 1964). No Brasil, ocorre nas regiões Norte, Nordeste e CentroOeste, ao longo dos biomas Amazônia, Caatinga e Mata Atlântica (Queiroz 2012).

Este estudo descreve e ilustra os frutos, sementes e plântulas de Canavalia dictyota e discute sua variação morfológica no gênero.

\section{MATERIAL E MÉTODOS}

Frutos maduros de Canavalia dictyota (Fig. 1a) foram obtidos a partir de espécime coletado em Roraima, Brasil. Abaixo, é referido o material testemunha da origem das sementes (exemplar adulto), seguido dos respectivos testemunhas de plântulas, todos tombados no Herbário do Museu Integrado de Roraima (MIRR): Flores 2163 (exemplar adulto), Rodrigues 2181 e Rodrigues 2182 (plântulas).

Fotografias foram tomadas com uma câmera Nikon D90, e as análises morfológicas e ilustrações foram feitas por meio de microscópio estereoscópico Nikon SMZ-800 com câmara clara. Medidas foram tomadas com uma paquímetro Mytutoyo. A terminologia descritiva de frutos e sementes seguiu Gunn (1981) e Kirkbride et al. (2003), exceto para "radícula", para a qual foi adotado o termo eixo hipocótilo-radícula (Meireles \& Tozzi 2008). Durante a preparação de material para dissecção, sementes foram hidratadas em água fervente por 30-90 s, dependendo da resistência da testa.

Sementes foram tratadas e germinadas em laboratório de acordo com Rodrigues et al. (2012). O termo plântula foi considerado segundo Parra (1984), como a fase transcorrida entre a germinação da semente até o aparecimento do metafilo. $\mathrm{O}$ grupo morfológico das plântulas foi classificado conforme Garwood (2009). As plantas jovens foram acompanhadas até o completo desenvolvimento da folha do terceiro nó foliar.

Foram medidas 30 plântulas de $C$. dictyota.
A terminologia morfológica foi baseada em Garwood (2009). Observações noturnas foram feitas para detectar a ocorrência de movimentos nictinásticos em folíolos (Rodrigues \& Tozzi 2008).

\section{RESULTADOS}

Os frutos, sementes e plântulas de Canavalia dictyota são ilustrados nas figuras 1-4.

\section{Morfologia do fruto de Canavalia dictyota}

Fruto do tipo legume, reto, unilocular, simples, seco, com estípite 11,4-12,8 x 3,44,7mm (Fig. 1B, 2A-C), com 4-7 sementes unisseriadas, septado, oblanceolado, achatado, 76,8-144,1 x 22,8-30,5 x 9,6-13,2mm, com partes florais persistentes, com textura geral coriácea, não torcido, na maturidade com fissuras diagonalmente dispostas (Fig. 2B), base cuneada assimétrica, ápice com rostro curvo 7,1-10,1 $\mathrm{mm}$ compr., as duas valvas deiscentes ao longo de toda sutura ventral (Fig. $2 \mathrm{D})$, cada valva com duas alas, as alas suturais com $0,9-1,8 \mathrm{~mm}$ larg. e as alas valvares com 0,6 $-0,10 \mathrm{~mm}$ larg. (Fig. 1B, 2B), câmaras seminíferas visíveis externamente. Exocarpo com coloração homogênea, castanho-alaranjada a marrom, esparsamente pubescente, com tricomas simples, alvos, ca. 0,3-0,6mm compr. Mesocarpo desenvolvido, ca. $0,8 \mathrm{~mm}$ de espessura, dividido em duas camadas, uma vítrea, mais externa, $0,4 \mathrm{~mm}$ de espessura, e outra sólida, $0,4 \mathrm{~mm}$ de espessura (Fig. 2E). Endocarpo ca. $0,3 \mathrm{~mm}$ de espessura, alvo, com textura papirácea, esfoliante em parte, apresentando-se fusionado ao mesocarpo e epicarpo (Fig. 1D, 2D-E); funículo 14,2-14,6 x 1,4-2,7mm, castanho-avermelhado.

\section{Morfologia da semente de Canavalia dictyota}

Semente com 14,8-17,5 x 9,7-12,3 x 6,3$9,3 \mathrm{~mm}$, simétrica, oblonga, comprimida lateralmente; testa glabra, lisa, coriácea, com coloração castanho-amarelada com manchas marrons, opaca a levemente brilhante, sem linhas de fraturas (Fig. 1C, 2F-G); lobo radicular e micrópila visíveis, lentes não discerníveis; hilo linear, lateral, 11,9-14,9 x 1,5 $-2,9 \mathrm{~mm}$, com linha fabóide (faboid split) (Fig. 2F-G), com arilo seco apresentando projeção laminar junto à micrópila (tongue aril) (Fig. $1 \mathrm{C}, 2 \mathrm{~F})$; endosperma ausente. Embrião com 

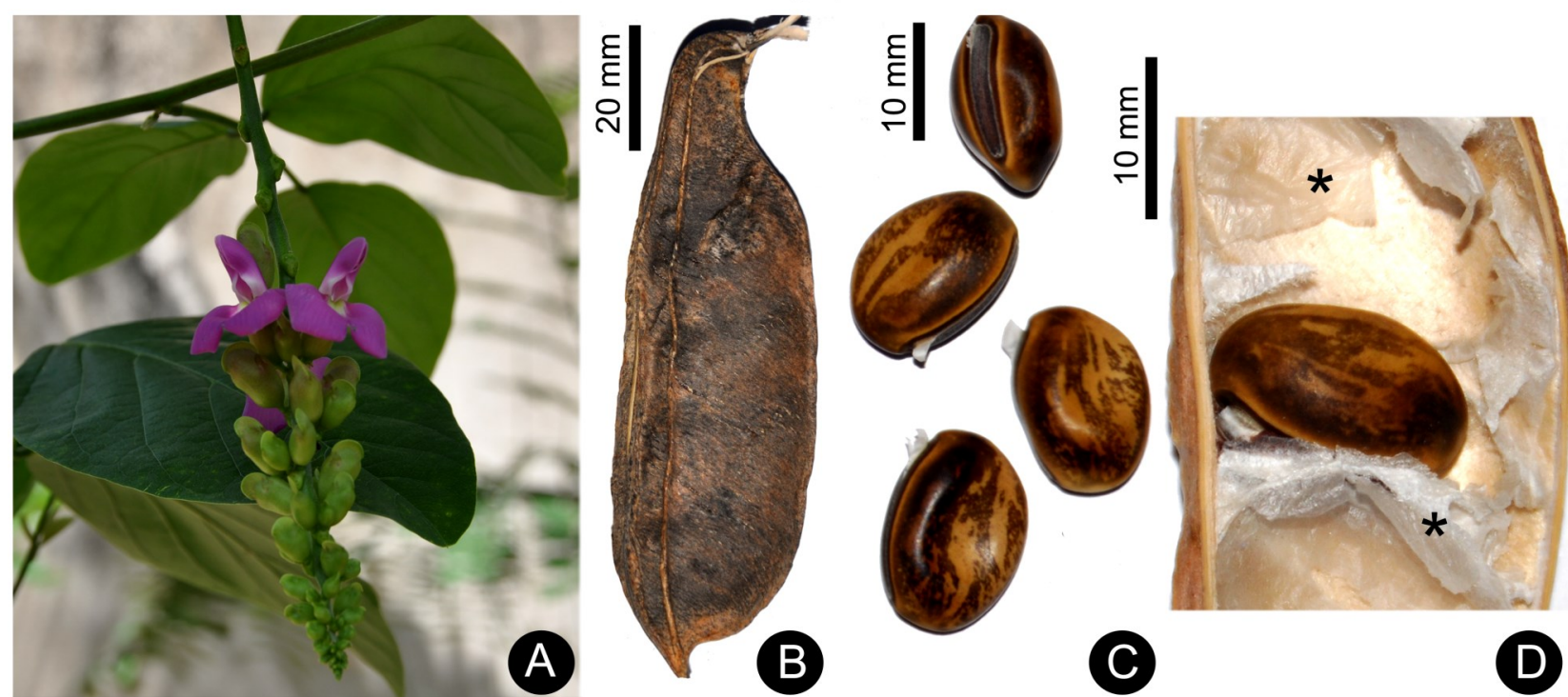

Figura 1. Morfologia de sementes e frutos de Canavalia dictyota Piper. A. Indivíduo adulto florido. B. Legume maduro. C. Sementes maduras. D. Detalhe de uma semente e sua posição no fruto, em destaque (asteriscos) o endocarpo com textura papirácea, esfoliante (Flores 2163, MIRR).

cotilédones lisos, glabros, oblongo-elípticos, 17,6-17,9 x 4,5-4,6mm, creme-esverdeados (Fig. 2J). Eixo hipocótilo-radícula triangular, exposto, 4,3-4,5 x 1,6-1,7mm, com menos de $1 / 2$ do comprimento dos cotilédones, disposto em ângulo de 90 graus com os cotilédones (Fig. $2 \mathrm{H}$ -I). Plúmula bem desenvolvida, esbranquiçada, lisa, glabra, com 2,2-2,3mm compr. (Fig. 2H).

\section{Desenvolvimento da plântula de Canavalia dictyota}

A partir da semeadura (Fig. 3A), ao serem expostas à umidade as sementes apresentaram escurecimento da testa após cinco horas, tornando-se enegrecidas e, no primeiro dia, aumentaram expressivamente seu tamanho (Fig. 3B).

A germinação das sementes iniciou um ou dois dias após a semeadura (Fig. 3C). O desenvolvimento das plântulas começou com o rompimento da testa junto à região da micrópila e a emergência do eixo hipocótilo-radícula. Com dois dias, ocorreu a fragmentação e o descarte parcial da testa e o alongamento da raiz principal (Fig. 3D). Com três dias, o hipocótilo começou a se alongar e ocorreu a emissão das primeiras raízes secundárias (Fig. 3E, 4A).

Quatro a seis dias após a germinação, o epicótilo começou a se alongar juntamente com um par de eofilos do primeiro nó (E1) (Fig. 3F$\mathrm{G})$. Inicialmente os eofilos estavam envolvidos pelos cotilédones (Fig. 3F-G), que mantiveram uma disposição perpendicular em relação ao solo, até cerca de cinco a oito dias após a germinação.

A total exposição e a posição horizontal dos cotilédones em relação ao solo se completaram seis a nove dias após a germinação. A completa expansão do epicótilo e do E1 se deu após 9-12 e 11-20 dias, respectivamente. (Fig. 3H-I). Concomitantemente, entre 15 a 19 dias, os cotilédones começaram sua senescência, deixando na plântula uma cicatriz no nó cotiledonar (Fig. 3I). Em resumo, em $C$. dictyota, as observações revelaram que, entre a germinação e o completo desenvolvimento do E1, decorreram 20 dias. Subsequentemente, os primeiros metafilos, 3-foliados e alternos, começaram sua expansão. A completa expansão dos metafilos do terceiro nó se deu em 30-40 dias após a germinação.

\section{Morfologia da plântula de Canavalia dictyota}

Plântula PER (fanero-epígea-reserva) (Fig. 3H). Raiz principal castanho-clara, não tuberizada. Hipocótilo 62-100 x 1,5-3mm, cilíndrico, verde, glabro (Fig. 4B). Cotilédones 19-25 x 11,8-16 × 5,5-7mm, armazenadores, carnosos, sésseis, obovados, plano-convexos, com base auriculada, não nictinásticos, verdes (Fig. 3G-H, 4B). Epicótilo 44,3-134,9 x 1,52,6mm, cilíndrico, verde-claro, glabro (Fig. 4B). E1 1-foliolados, opostos, os metafilos subsequentes alternos e 3-foliolados (Fig. 3I). Estípulas do E1 2,9-6 x 3,6-6mm, inteiras ou bilobadas no ápice (Fig. 3I, 4C). E1 com pecíolo 12,4-59,4 x 1,1-1,6mm, pulvino 2,1- 


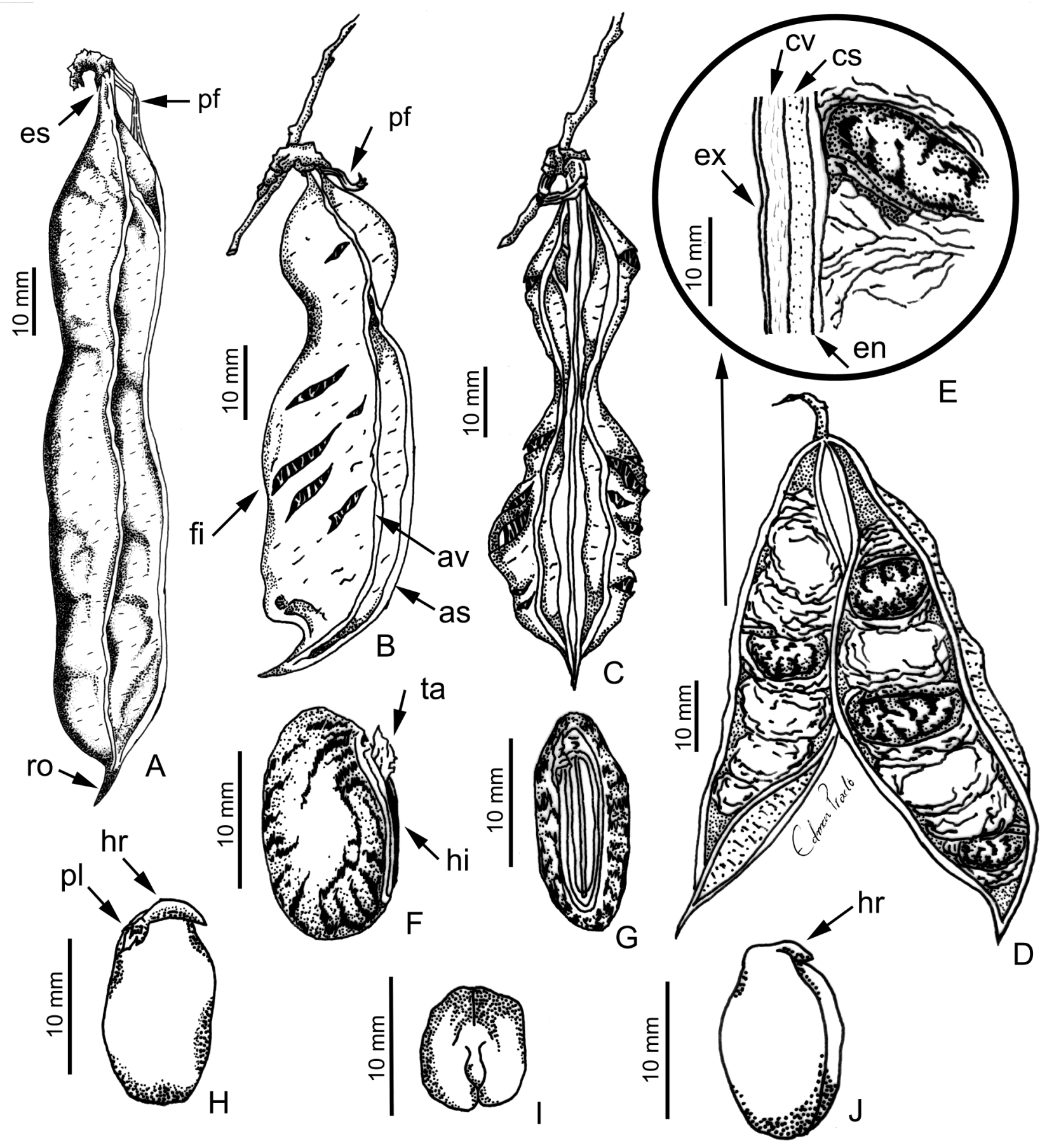

Figura 2. Morfologia de sementes e frutos de Canavalia dictyota Piper. A-B. Vista lateral dos legumes. C. Vista ventral do legume. D. Legume após sua deiscência. E. Detalhe de uma semente e sua posição no fruto. F-G. Semente. H. Embrião (com um cotilédone retirado). I-J. Embrião. as= ala sutural; av= ala valvar; $\mathrm{cs}=$ camada sólida do mesocarpo; $\mathrm{cv}=$ camada vítrea do mesocarpo; eixo hipocótilo-radícula; en=endocarpo; es= estípite; ex=exocarpo; fi= fissuras no exocarpo; hi=hilo; pf= partes florais persistentes; pl=plúmula; ro= rostro; ta= tongue aril, arilo seco e com projeção laminar junto à micrópila (Flores 2163, MIRR). 

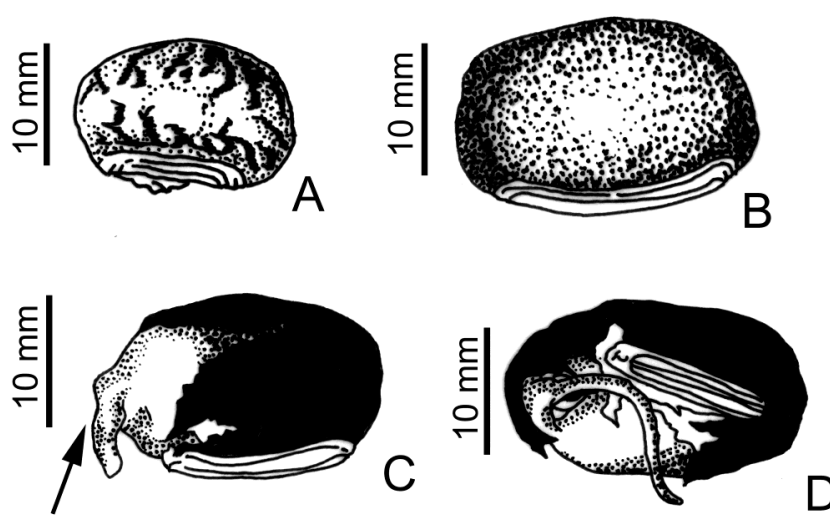

$\mathrm{hr}$
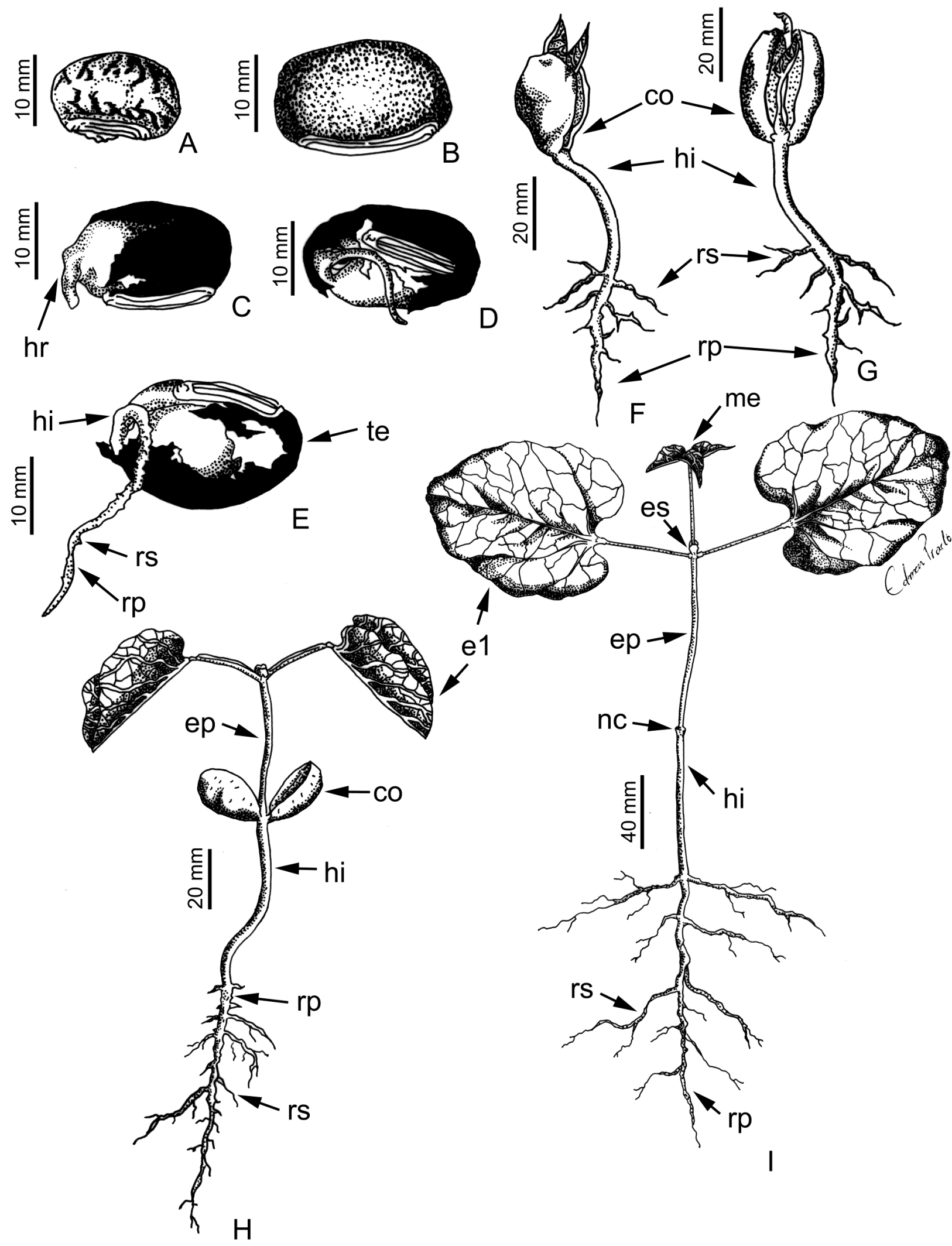

Figura 3. Morfologia e desenvolvimento de plântulas de Canavalia dictyota Piper. A. Semente. B. Semente com tamanho aumentado (1 dia). C. Germinação, com emissão do eixo hipocótilo-radícula (2 dias). D. Fragmentação e o descarte parcial da testa e o alongamento da raiz principal. E. Alongamento do hipocótilo e início da emissão das raízes secundárias ( 3 dias). F-G. Alongamento do epicótilo e do par de eofilos do primeiro nó (6 dias). H. Completa expansão do epicótilo (12 dias). Completa expansão do par de eofilos do primeiro nó (20 dias). $\mathrm{co}=$ cotilédone; e1= eofilo do primeiro nó; ep= epicótilo; ep= epicótilo; es= estípula; hi= hilo; hi= hipocótilo; $\mathrm{hr}=$ eixo hipocótilo-radícula; $\mathrm{me}=$ metafilo; $\mathrm{nc}=$ nó cotiledonar; $\mathrm{rp}=$ raiz principal; $\mathrm{rs}=$ raiz secundária; te $=$ testa (Rodrigues $2181 \mathrm{MIRR}$ ). 

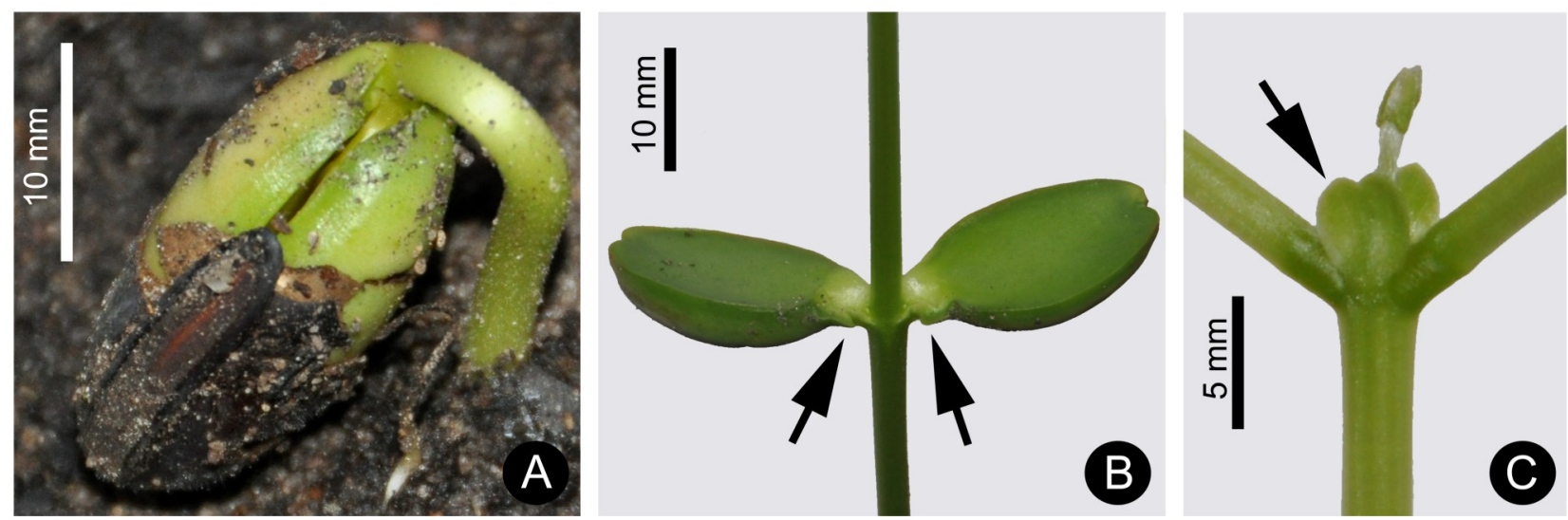

Figura 4. Morfologia e desenvolvimento de plântulas de Canavalia dictyota Piper. A. Plântula (3 dias). B. Detalhe da plântula, em destaque (setas) as aurículas na base dos cotilédones. C. Detalhe (seta) das estípulas bilobadas dos eofilos do primeiro nó.

2,3mm compr. e pulvínulo 1,6-1,9mm compr.; que permitiram a distinção entre estas espécies lâmina do folíolo 65,2-130 x 60-110mm, oval, foram a forma e as dimensões dos primeiros base lobada, ápice arredondado, glabros a eofilos e, adicionalmente, a forma das estípulas glabrescentes em ambas as faces, não e o comprimento do hipocótilo. Entretanto, para nictinásticos (Fig. 3I). Estípulas dos metafilos os neotrópicos existem dados comparáveis para (até o terceiro nó foliar) 1,5-3 x 1,4-3,2mm, somente três espécies, C. ensiformis (Baudet inteiras ou bilobadas no ápice. Metafilos com 1974), C. rosea (Gonçalves et al. 2008) e $C$. pecíolo 30-40 x 1,5-1,7mm, pulvino 4-5 mm dictyota (presente trabalho). Para C. parviflora compr.e pulvínulo 3-4mm compr.; lâmina do Benth., somente é mencionada informação sobre folíolo terminal 70-80 x 35-40mm, dos laterais suas o grupo morfológico de suas plântulas 50-65 x 30-35mm, elíptica, base e ápice (PER) (Sanches \& Válio 2002). Assim, com arredondados, glabros a glabrescentes em ambas exceção do epicótilo pubescente em $C$. as faces, não \nictinásticos.

\section{DISCUSSÃO}

No que se refere aos frutos e sementes, ensiformis e glabro em $C$. rosea e C. dictyota, não foram encontradas outras características distintivas na morfologia de plântulas destas três espécies.

Com o presente trabalho e os dados de nossos resultados concordam com a variação Compton (1912), Baudet (1974), Sastraprajda et encontrada para o gênero, de acordo com al. (1976), Sanches \& Válio (2002) e Gonçalves Kirkbride et al. (2003).

et al. (2008), existem dados de morfologia de

A germinação de Canavalia dictyota se deu plântulas para nove espécies de Canavalia cujas num período inferior a quatro semanas, sendo principais características são: plântulas PER, E1 considerada como uma germinação imediata 1-foliolados, opostos, com base lobada, cordada (Garwood 1995). Adicionalmente, o início da ou truncada e estípulas simples (com ápice germinação de Canavalia dictyota é semelhante inteiro ou bífido); epicótilo glabro ou ao observado para $C$. rosea (Gonçalves et al. pubescente, com tricomas simples; estipelas 2008).

Com relação às plântulas de Canavalia, Em conclusão, Canavalia dictyota têm suas Sastraprajda et al. (1976) realizaram um plântulas descritas pela primeira vez e os dados trabalho comparativo entre a variação aqui apresentados ampliam o conhecimento morfológica dos caracteres de plântulas de disponível na literatura para o gênero. Desta espécies de Canavalia ocorrentes na ilha de Java forma, o tipo morfológico de plântulas, número (Indonésia). Neste trabalho, todas as seis de folíolos e ausência de estipelas no E1 espécies estudadas (C. gladiata (Jacq.) DC., C. parecem ser conservativos em Canavalia, o que ensiformis, C. microcarpa (DC.) Piper, $C$. não ocorre em alguns outros gêneros da tribo virosa (Roxb.) Wight \& Arn, C. maritima Phaseoleae, como por exemplo, em Centrosema (Aubl.) Thouars e C. sp.) foram diagnosticadas Benth., Phaseolus L. e Rhynchosia Lour. como do grupo PER. Os principais caracteres (Baudet 1974; Rodrigues et al. 2012). 


\section{AGRADECIMENTOS}

Este trabalho é parte da monografia de Bacharelado em Ciências Biológicas-UFRR (ênfase em Biologia Vegetal) do primeiro autor. Os autores agradecem ao CBio/UFRR pelas facilidades ao seu desenvolvimento.

\section{REFERÊNCIAS BIBLIOGRÁFICAS}

Baudet, J.C. 1974. Signification taxonomique des caracteres blastogèniques dans la tribu des Papilionaceae -Phaseoleae. Bulletin $d u$ jardin botanique national de Belgique 44: 259-293.

Beyra, A.; Reyes, G.; Hernández, L. \& Herrera, P. 2004. Revisión taxonómica del género Canavalia DC. (Leguminosae - Papilionoideae) en Cuba. Revista de la Academia Colombiana de Ciencias 28: 157-175.

Compton, R.H. 1912. An investigation of the seedling structure in the Leguminosae. The Journal of the Linnean Society (Botany) 41: 1-122.

Duke, J.A. \& Polhill, R.M. 1981. Seedlings of Leguminosae. In: Polhill, R.M. \& Raven, P.H. (Ed.). Advances in Legume Systematics, Part 2. Royal Botanic Gardens, Kew, p. 941-949.

Garwood, N.C. 1995. Studies in Annonaceae. XX. Morphology and ecology of seedlings, fruits and seeds of selected Panamanian species. Botanische Jahrbücher und Systematik 117: 1-152.

Garwood, N.C. 2009. Seedlings of Barro Colorado Island and the Neotropics. Comstock Publishing Associates, Ithaca, 645p.

Gonçalves, I.P.; Gama, M.C.; Correia, M.C.R. \& Lima H.A. 2008. Caracterização dos frutos, sementes e germinação de quatro espécies de leguminosas da restinga de Maricá, Rio de Janeiro. Rodriguésia 59: 497-512.

Gunn, C.R. 1981. Seeds of Leguminosae. In: Polhill, R.M. \& Raven, P.H. (Ed.). Advances in Legume Systematics, Part 2. Royal Botanic Gardens, Kew, p. 913-925.

Gunn, C.R. 1984. Fruits and seeds of genera in the subfamily Mimosoideae (Fabaceae). United States Department of Agriculture Technical Bulletin 1681: 1194.

Gurgel, E.S.C.; Santos, J.U.M.; Lucas, F.C.A. \& Bastos, M.N.C. 2012. Morfologia de plântulas de Leguminosae e o potencial sistemático. Rodriguésia 63: $65-73$

Kirkbride, J.H.; Gunn, C.R. \& Weitzman, A.L. 2003. Fruits and seeds of genera in the subfamily Faboideae (Fabaceae). United States Department of Agriculture Technical Bulletin 1890: 1-1208.

Lewis, G.; Schrire, B.; Mackinder, B. \& Lock, M. 2005. Legumes of the World. Royal Botanic Gardens, Kew, $577 \mathrm{p}$.
Lima, H.C. 1990. Tribo Dalbergieae (Leguminosae Papilionoideae) - Morfologia dos frutos, sementes e plântulas e sua aplicação na sistemática. Arquivos do Jardim Botânico do Rio de Janeiro 30: 1-42.

Meireles, J.E. \& Tozzi, A.M.G.A. 2008. Seed and embryo morphology of Poecilanthe (Fabaceae, Papilionoideae, Brongniartieae). Botanical Journal of the Linnean Society 158: 249-256.

Oliveira, D.M.T. 1999. Morfologia de plântulas e plantas jovens de 30 espécies arbóreas de Leguminosae. Acta Botanica Brasilica 13: 263-269.

Oliveira, D.M.T. 2001. Morfologia comparada de plântulas e plantas jovens de leguminosas arbóreas nativas: espécies de Phaseoleae, Sophoreae, Swartzieae e Tephrosieae. Revista Brasileira de Botânica 24: 85-97.

Parra, P. 1984. Estudio de la morfologia externa de plántulas de Calliandra gracilis, Mimosa albida, Mimosa arenosa, Mimosa camporum y Mimosa tenuiflora. Revista de la Faculdad de Agronomia (Maracay) 13: 311-350.

Queiroz, L.P. 2012. Canavalia (http:// floradobrasil.jbrj.gov.br/2012/FB022854). Acesso em 10/12/2012.

Rodrigues, R.S. \& Tozzi, A.M.G.A. 2008. Systematic relevance of seedling morphology in Acosmium, Guianodendron, and Leptolobium (Leguminosae, Papilionoideae). Brittonia 60: 287-296.

Rodrigues, R.S.; Hirt, A.P.M \& Flores, A.S. 2012. Morfologia de plântulas das espécies de Rhynchosia (Leguminosae, Papilionoideae) de Roraima, Brasil. Acta Botanica Brasilica 26: 585-592.

Sanches, M.C. \& Válio, I.F.M. 2002 Seed and seedling survival of some climber species in a southeast Brazilian tropical forest. Biotropica 34: 323-327.

Sauer, J. 1964. Revision of Canavalia. Brittonia 16: 106181.

Schrire 2005. Tribe Phaseoleae. In: Lewis, G.; Schrire, B.; Mackinder, B. \& Lock, M. 2005. Legumes of the World. Royal Botanic Gardens, Kew, p. 393-431. 